\title{
The Physician Global Assessment and Body Surface Area composite tool is a simple alternative to the Psoriasis Area and Severity Index for assessment of psoriasis: post hoc analysis from PRISTINE and PRESTA
}

This article was published in the following Dove Press journal: Psoriasis: Targets and Therapy

\author{
Jessica A Walsh' \\ Heather Jones ${ }^{2}$ \\ Lotus Mallbris ${ }^{2}$ \\ Kristina Callis Duffin ${ }^{3}$ \\ Gerald G Krueger ${ }^{3}$ \\ Daniel O Clegg' \\ Annette Szumski ${ }^{4}$ \\ 'Division of Rheumatology, \\ Department of Internal Medicine, \\ University of Utah School of \\ Medicine, Salt Lake City, UT, USA; \\ ${ }^{2}$ Inflammation and Immunology, Global \\ Medical Affairs, Pfizer, Collegeville, PA, \\ USA; ${ }^{3}$ Department of Dermatology, \\ University of Utah School of \\ Medicine, Salt Lake City, UT, USA; \\ ${ }^{4}$ Pfizer Business Unit (PBU) Syneos \\ Health, Princeton, NJ, United States
}

Correspondence: Jessica A Walsh Division of Rheumatology, Department of Internal Medicine, School of Medicine, University of Utah, George E Wahlen Veterans Affairs Medical Center, Room 4B200, 30 N I 900 E, Salt Lake City, UT 84132 , USA

Tel + I 80I 58I 7724

Email jessica.walsh@hsc.utah.edu
Background: The product of Physician Global Assessment and Body Surface Area (PGA $\times$ BSA) is a new outcome measure for psoriasis severity and response to therapy. The objective of this study was to evaluate PGA $\times$ BSA as an alternative to Psoriasis Area and Severity Index (PASI) for psoriasis assessments.

Methods: The relationship between PASI and PGA $\times$ BSA was assessed in a post hoc analysis of pooled data from the PRISTINE (NCT00663052) and PRESTA (NCT00245960) trials in patients with moderate-to-severe psoriasis who received etanercept $50 \mathrm{mg} /$ week. Data were analyzed using Spearman and intra-class correlation coefficients, effect sizes, scatterplots, Bland-Altman plots, and Kappa statistics.

Results: Spearman correlations at baseline, week 12, and week 24 were strong for PGA $\times$ BSA versus PASI ( $r=0.78,0.87$, and 0.90 , respectively; all $P<0.0001)$ as were intra-class correlations (0.76 [95\% confidence interval 0.73-0.80], 0.80 [0.76-0.83], and 0.85 [0.82-0.87], respectively). The effect size was -1.53 for PASI and -0.94 for PGA $\times$ BSA (baseline to week 24 ). Scatterplots and Bland-Altman plots detected a trend across the range of measurement. Kappa statistics (at 12 and 24 weeks) between PASI50/75/90 and 50/75/90\% improvement in PGA $\times$ BSA showed good agreement ( $0.58-0.69$ at week 12 and $0.63-0.67$, respectively; all $P<0.0001)$. At baseline, the Spearman correlation coefficients were $0.96,0.51,0.19$, and 0.17 for PGA $\times$ BSA versus BSA, PGA, Patient Global Assessment, and Dermatology Life Quality Index, respectively (all $P<0.001$ ).

Conclusion: PGA $\times$ BSA has advantages over PASI for measuring moderate-to-severe psoriasis; it is intuitive, sensitive, and easy to use.

Keywords: etanercept, PASI, PGA $\times$ BSA, psoriasis, correlation, agreement, responsiveness

\section{Background}

The most commonly used psoriasis outcome measures do not individually capture all aspects of psoriatic disease and are of limited use in clinical practice. ${ }^{1}$ Specifically, Psoriasis Area and Severity Index (PASI) is considered impractical for everyday clinical practice because it is complicated to calculate, difficult to interpret, time consuming, and insensitive in mild psoriasis. ${ }^{2}$ Physician Global Assessment (PGA) is more practical; however, its value as a stand-alone instrument is limited because 
it does not assess the extent of body surface involvement. Likewise, Body Surface Area (BSA) is not suitable as a sole outcome measure because it does not measure the quality or morphology of lesions. In an evolving climate of outcomebased clinical practice, ${ }^{3}$ there remains an unmet need for a practical, uniform, validated, and standardized outcome measure of psoriasis for use in both clinical practice and clinical trials. ${ }^{1,4-6}$

The product of PGA and BSA $(\mathrm{PGA} \times \mathrm{BSA})$ has previously been reported by our group as a simple and sensitive instrument for measuring psoriasis severity. ${ }^{2}$ However, response to therapy could not be assessed in that observational registry study because the participants were on many different therapies and were not evaluated at predefined time intervals, which would be necessary for evaluating response to therapy over time. Additionally, the previous study was limited because of low numbers of participants with severe psoriasis. PGA $\times$ BSA, also known as Simple-Measure for Assessing Psoriasis Activity, is increasingly being used as a simple measure for psoriasis severity. ${ }^{7-11}$

The objective of this post hoc analysis was to evaluate PGA $\times$ BSA as a simpler alternative to PASI for measuring psoriasis severity and response to therapy.

\section{Methods}

\section{Study design}

Data were pooled from two randomized, controlled trials, PRISTINE (NCT00663052) ${ }^{12}$ and PRESTA (NCT00245960), ${ }^{13}$ in patients with moderate-to-severe psoriasis. These two studies were selected for the current analysis because participants were on a predefined treatment regimen and PASI, PGA, and BSA measurements were recorded at weeks 0, 12, and 24 in both studies, thus allowing analysis of PGA $\times$ BSA as a static measure of disease activity at baseline and as a measure of response to therapy over time. The study design and primary outcomes of both trials have been described in detail previously. ${ }^{12,13}$ Patients received double-blind etanercept $50 \mathrm{mg}$ twice weekly or once weekly for 12 weeks, then open-label etanercept $50 \mathrm{mg} /$ week for 12 weeks. This retrospective analysis was conducted on the pooled etanercept $50 \mathrm{mg} /$ week group in the modified intention-to-treat population at baseline, and weeks 12 and 24 .

Both trials were conducted in accordance with the ethical principles of the Declaration of Helsinki and all patients signed and dated an approved informed consent form prior to participation in the trial. Regional Institutional Review Boards (IRBs)/Independent Ethics Committees (IECs) reviewed and approved the study protocols (Table S1).

\section{Assessments}

PGA was a global assessment of all lesions scored on a scale of $0-5$ in both trials, with 0 representing clear skin, 1 almost clear skin, and 5 representing severe psoriasis. ${ }^{12,13}$ BSA was defined as the percent of BSA involvement, where $1 \%$ is approximately the area of the patient's handprint. The PASI score consisted of the sum of the erythema, induration, and desquamation for each body region, multiplied by weighted area scores. ${ }^{14}$ Patient Global Assessment (PtGA) was scored on a scale of 1-100 in the PRESTA study and 0-5 in the PRISTINE study. The scale for PtGA in the PRESTA study was converted from $0-100$ to $0-5$ by dividing by 20 . The Dermatology Life Quality Index (DLQI) is a validated patient-reported instrument that contains 10 questions used to assess the impact of skin disease on health-related quality of life and daily activities, with total scores ranging from 0 to 30 and higher scores indicating greater impairment of quality of life. ${ }^{15}$

\section{Statistical analysis}

PASI was used as the reference standard since it is frequently used as an efficacy endpoint in clinical trials and has been widely considered as the standard for measuring psoriasis severity. Means and standard deviation (SD), medians, frequencies, and percentages were used to describe samples. Chi-square or Fisher's exact tests were performed to compare categorical variables, and one-way analysis of variance with treatment as a factor was used to compare continuous variables.

Correlations between PASI and PGA $\times$ BSA were evaluated using Spearman correlation coefficients. Agreement was evaluated with intra-class correlation coefficients (ICCs), scatterplots, Bland-Altman plots, and Cohen's Kappa coefficients. For the Spearman correlation coefficients and ICCs, values of $0.30-0.50,0.50-0.70,0.70-0.90$, and $\geq 0.90$ roughly correspond to low, moderate, high, and very high correlation or agreement, respectively. ICCs differ from Spearman correlations in that ICCs take into account both correlation and the difference in values, whereas Spearman correlations take into account only the correlation. For example, parameter 1 might have values of $1,2,3$, and parameter 2 might have values of $3,4,5$. Spearman coefficients would give a correlation of 1.0 (perfectly correlated with identically sloping lines). However, the ICC would be lower because it also takes into account the differences in the values (the lines are not superimposed).

For each assessment, responsiveness to change was assessed using effect size estimates, with larger effect size indicating greater responsiveness to change. Effect size was 
calculated as the difference between the post-baseline mean and the baseline mean scores divided by the baseline SD.

Scatterplots and Bland-Altman plots were used to visually detect systemic differences and trends between PASI and $\mathrm{PGA} \times \mathrm{BSA}$. In order to make the instruments comparable, PGA $\times$ BSA (scale 0-500) needed to be placed on the same scale as PASI (0-72) by dividing all PGA $\times$ BSA values by a constant factor (6.94) for some of the analyses. For scatterplots, the diagonal line represents the line of agreement, and data points that are dispersed above or below this line would indicate that PGA $\times$ BSA underestimates or overestimates psoriasis severity, respectively, when PASI is used as the reference standard. For Bland-Altman plots, the differences between PASI and PGA $\times$ BSA were plotted against the averages of these two assessments, along with vertical lines to denote the mean difference and its $95 \%$ limit of agreement (defined as the mean difference $\pm 1.96 * \mathrm{SD}$ ). Good agreement is indicated in a Bland-Altman plot by a small mean difference and low dispersion around the mean difference line and no apparent correlation between the average and the difference. Increasing or decreasing trends in the Bland-Altman plots would indicate that the level of agreement differs across the range of instrument scores.

Concordance between PASI50/75/90 and PGA $\times$ BSA50/75/90 was defined as the percentage of patients achieving specific outcomes as measured by each instrument; that is, the percentage of patients who achieved $>$ PASI50/75/90 and >50/75/90\% improvement for PGA $\times$ BSA $($ PGA $\times$ BSA50/75/90) plus the percentage of patients who were below the threshold for both measures (< PASI50/75/90 and $<$ PGA $\times$ BSA50/75/90).

Correlations between PGA $\times$ BSA and BSA, PGA, PtGA, and DLQI were evaluated using Spearman correlation coefficients at baseline, week 12, and week 24 .
The data analysis software UNIX SAS ${ }^{\circledR}$ version 9.2 (SAS Institute Inc., Cary, NC, USA) was used for statistical analyses.

\section{Results}

The mean age in the pooled patient group $(\mathrm{N}=510)$ was 46.1 years and $64.9 \%$ of patients were male. The mean duration of psoriasis was 18 years and the median BSA involvement was $22.0 \%$ (Table 1 ). Spearman correlation coefficients (Table 2) for PASI versus PGA $\times$ BSA were statistically significant $(P<0.0001)$ and ranged from 0.78 (baseline) to 0.90 (week 24). ICC coefficients ranged from 0.76 to 0.85 (Table 2 ).

Scatterplots between PASI and PGA $\times$ BSA at baseline and week 24 are shown in Figure $1 \mathrm{~A}$ and B, respectively. Most of the data points fell above the line of agreement at

Table I Baseline demographic and disease characteristics

\begin{tabular}{|c|c|}
\hline Characteristics & $\begin{array}{l}\text { Etanercept } 50 \mathrm{mg} / \text { week } \\
(\mathrm{N}=5 \mathrm{I0})\end{array}$ \\
\hline Age, years & 46.I (I I.8) \\
\hline Male, n (\%) & 331 (64.9) \\
\hline Body mass index, kg/m² & $28.6(5.7)$ \\
\hline \multicolumn{2}{|l|}{ Race, n (\%) } \\
\hline Asian & $53(10.4)$ \\
\hline White & $421(82.5)$ \\
\hline Other & $36(7.1)$ \\
\hline Duration of psoriasis, years & $18.0(11.2)$ \\
\hline Diagnosis of psoriatic arthritis, $\mathrm{n}(\%)$ & $412(80.8)$ \\
\hline Duration of psoriatic arthritis, years & $7.3(7.3)$ \\
\hline PGA of psoriasis & $3.6(0.7)$ \\
\hline Affected BSA, $\%$ median (min, max) & $22.0(9.0,92.5)$ \\
\hline PASI & $19.5(9.7)$ \\
\hline$P G A \times B S A$ & I I $5.0(95.4)$ \\
\hline
\end{tabular}

Note: Values are mean (standard deviation) unless otherwise stated.

Abbreviations: BSA, Body Surface Area; PASI, Psoriasis Area and Severity Index; PGA, Physician Global Assessment.

Table 2 Correlations, agreement, and responsiveness to change between PASI and PGA $\times$ BSA

\begin{tabular}{|c|c|c|c|c|c|c|}
\hline \multirow[t]{2}{*}{ Time } & \multicolumn{2}{|l|}{ PASI } & \multicolumn{2}{|l|}{ PGA $\times$ BSA } & \multirow{2}{*}{$\begin{array}{l}\text { PASI versus } \\
\mathbf{P G A} \times \mathbf{B S A} \\
r\end{array}$} & \multirow{2}{*}{$\begin{array}{l}\text { PASI versus rescaled } \\
\text { PGA } \times \text { BSA } \\
\text { ICC }(95 \% \mathrm{CI})\end{array}$} \\
\hline & Mean (SD) & Effect size & Mean (SD) & Effect size & & \\
\hline Baseline $(\mathrm{N}=493)$ & $19.6(9.7)$ & - & $115.6(96.2)$ & - & $0.78 *$ & $0.76(0.73-0.80)$ \\
\hline Week I2 (N=493) & $7.2(6.4)$ & - & $41.9(56.6)$ & - & $0.87^{*}$ & $0.80(0.76-0.83)$ \\
\hline Week I 2 CFB (N=493) & $-12.3(8.5)$ & -1.27 & $-73.7(73.3)$ & -0.77 & $0.78^{*}$ & - \\
\hline Baseline $(\mathrm{N}=470)$ & $19.6(9.8)$ & - & II $5.6(96.2)$ & - & - & - \\
\hline Week $24(\mathrm{~N}=470)$ & $4.6(5.6)$ & - & $25.2(44.3)$ & - & $0.90 *$ & $0.85(0.82-0.87)$ \\
\hline Week 24 CFB $(N=470)$ & $-15.0(9.5)$ & -1.53 & $-90.4(85.2)$ & -0.94 & $0.77 *$ & - \\
\hline
\end{tabular}

Notes: $* P<0.000$ I. Modified intention-to-treat population, observed cases by treatment. $N=$ patients with baseline, week I2, or week 24 values. Effect size was calculated as the ratio of the difference between post-baseline and baseline mean scores, divided by baseline SD. Higher effect sizes suggest more responsiveness to change.

Abbreviations: BSA, Body Surface Area; CFB, change from baseline; Cl, confidence interval; ICC, intra-class correlation coefficient; PASI, Psoriasis Area and Severity Index; PGA, Physician Global Assessment; $r$, Spearman correlation coefficient; SD, standard deviation. 
A

Baseline

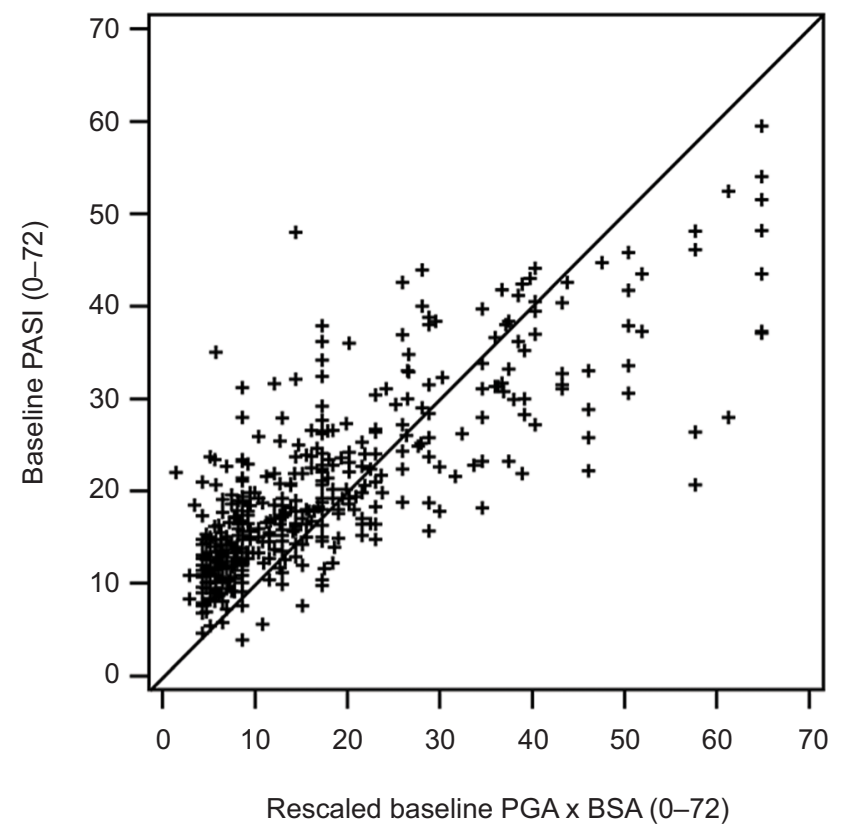

B

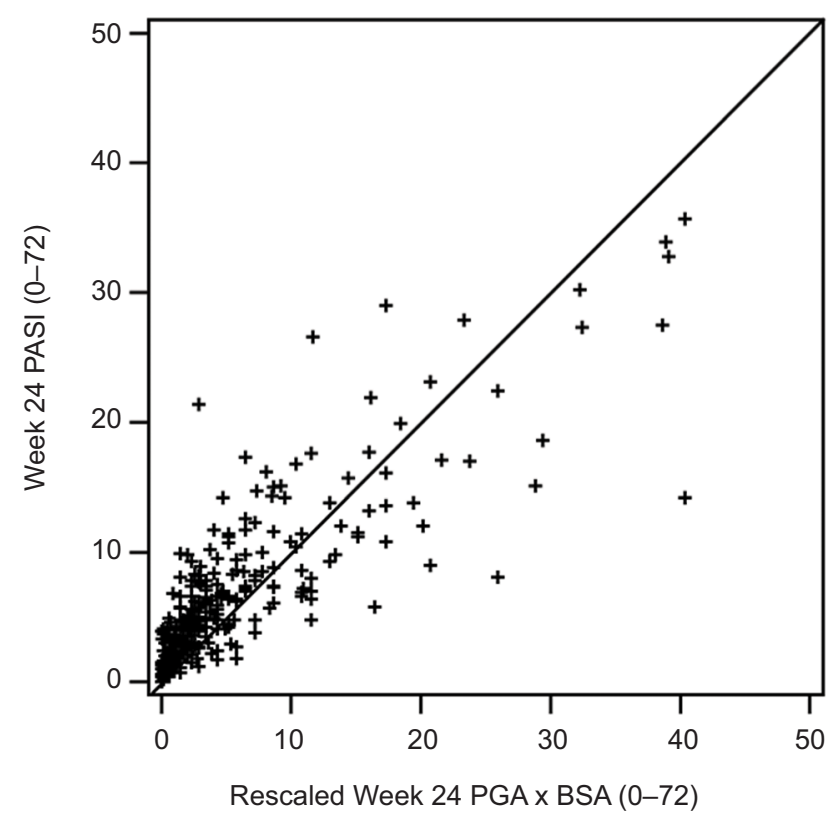

Figure I PASI versus PGA $\times$ BSA scatterplots at baseline (A) and week 24 (B). Abbreviations: BSA, Body Surface Area; PASI, Psoriasis Area and Severity Index; PGA, Physician Global Assessment.

the low end of the scale and below the line of agreement at the high end of the scale, demonstrating that psoriasis was rated more severely with PASI than scaled PGA $\times$ BSA at the low end of the scale and less severely at the high end. The magnitude of agreement between the instruments was further quantified with Bland-Altman plots at baseline (Figure 2A) and week 24 (Figure 2B). At both time points, as the average increased, a decreasing trend from positive to negative differences and more observations falling below the expected 95\% lower bound of agreement can be seen.

Concordance between PASI50/75/90 and PGA $\times$ BSA50/75/90 at week 12 and week 24 is shown in Figure 3. An overall concordance $>80 \%$ (that is, agreement, which included both PASI50/75/90 and PGA $\times$ BSA50/75/90 response and nonresponse) was achieved at both week 12 and 24. Among the patients who were discordant (that is, disagreement, which included both underrated and overrated responses), a greater percentage of patients achieved improvement with PGA $\times$ BSA50/75/90 than with PASI50/75/90 (overrated), at all time points except at week 12 for PGA $\times$ BSA50. Cohen's Kappa coefficients ranged from 0.58 to 0.69 at week 12 and from 0.63 to 0.67 at week 24 (all $P<0.0001)$.

Spearman correlation coefficients between PGA $\times$ BSA and other measures of psoriasis (Table 3 ) indicated very high correlations for $\mathrm{PGA} \times \mathrm{BSA}$ versus $\mathrm{BSA}$, moderate to high correlations for PGA $\times$ BSA versus PGA, and low to moderate correlations for PGA $\times$ BSA versus PtGA and DLQI.

\section{Discussion}

The aim of this study was to evaluate the use of PGA $\times$ BSA as an alternative to PASI for measuring psoriasis severity and response to therapy. The results demonstrated strong correlation (from Spearman correlation coefficients) and strong agreement (from ICC statistics) between PASI and PGA $\times$ BSA in measuring psoriasis severity. ${ }^{16-18}$ Additionally, the correlations found between PASI and PGA $\times$ BSA in this study $(r=0.78-0.90)$ are consistent with those in our earlier study $(r=0.87 \text { in all patients })^{2}$ as well as those reported in a recent post hoc analysis of data from the ESTEEM 1 and 2 studies $(r=0.74-0.84) .{ }^{10}$ The ICCs in the current study ( $\mathrm{ICC}=0.76-0.85)$ were also similar to those reported in the ESTEEM studies (ICC $=0.80-0.92) .{ }^{10}$

This study is unique in evaluating PGA $\times$ BSA and PASI scores across the range of psoriasis severity. The scatterplots show that $\mathrm{PGA} \times \mathrm{BSA}$ underestimates psoriasis severity relative to PASI for the low end of the scale and it overestimates psoriasis severity relative to PASI for the high end of the scale. This is supported by the Bland-Altman plots, which show that the differences between PGA $\times$ BSA and PASI are not constant across the range of measurement. While the magnitude of these differences was not large, PGA $\times$ BSA should not be considered an exact surrogate for PASI. The high rate of concordance (81.5\%-91.7\%) and corresponding Kappa statistics showed that there was good agreement between PGA $\times$ BSA50/75/90 and PASI50/75/90. ${ }^{18,19}$ PASI50/75/90 and PGA $\times$ BSA50/75/90 concordance and discordance data 
A

Baseline

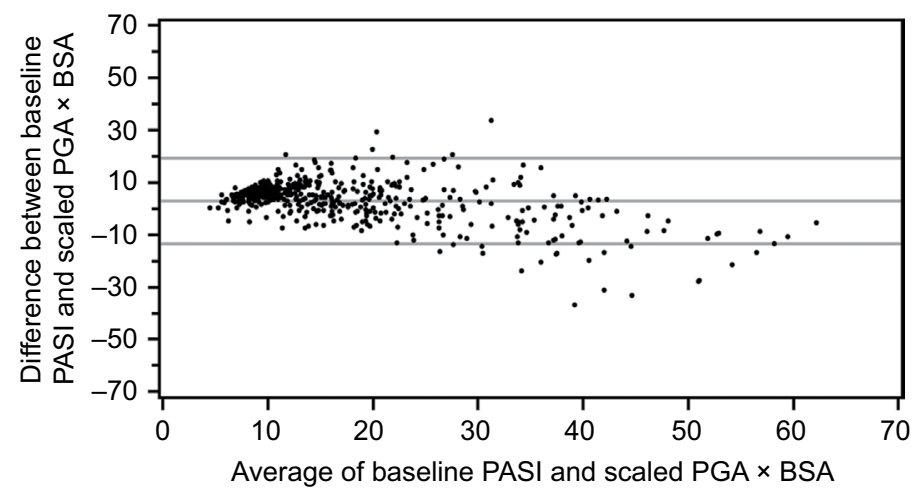

B

Week 24

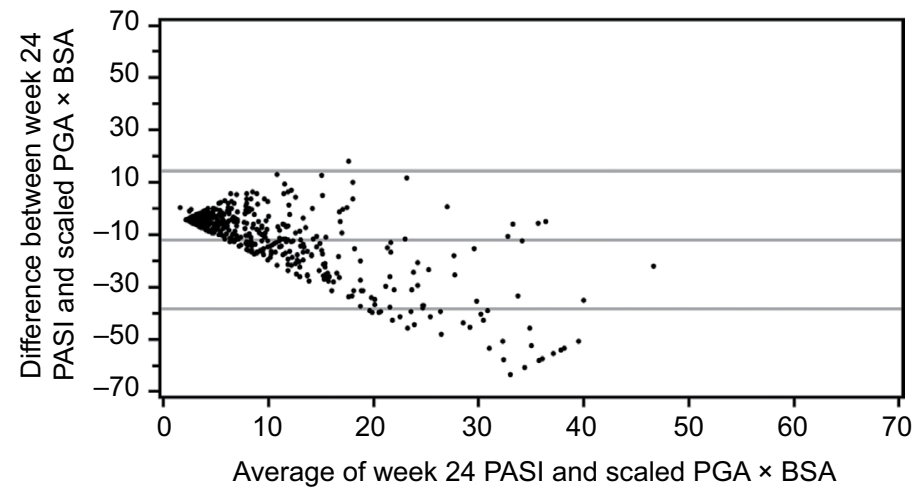

Figure 2 Bland-Altman plots at baseline (A) and week 24 (B).

Abbreviations: BSA, Body Surface Area; PASI, Psoriasis Area and Severity Index; PGA, Physician Global Assessment.

from this study were in a similar range to those reported at week 16 in the ESTEEM studies. ${ }^{10}$

In this study, PGA $\times$ BSA had strong correlations with the component measure BSA, moderate/strong correlations with the component measure PGA, and low/moderate correlations with patient-reported measures (PtGA and DLQI), which has also been reported in other studies. ${ }^{9,10}$ The strong correlations between $\mathrm{PGA} \times \mathrm{BSA}$ and $\mathrm{BSA}$ demonstrated that $\mathrm{PGA} \times \mathrm{BSA}$ and BSA measure psoriasis severity similarly at the population level. However, on an individual level, PGA $\times$ BSA would be better at differentiating disease severity with regard to different plaque morphologies. For example, patient A with severe plaque morphology (PGA of 4 ) over a surface area of $10 \%$ will have a PGA $\times$ BSA score of 40 and a BSA of $10 \%$, whereas patient $B$ with mild plaque morphology (PGA 1) and identical surface area will have a lower PGA $\times$ BSA score of 10 , but an identical (non-differentiating) BSA of $10 \%$. The ability of PGA $\times$ BSA to capture changes in both plaque morphology and surface area is particularly important when measuring response to treatment, since plaque morphology and area may improve at different rates after treatment initiation.

This study was limited because inter-rater reliability, used to assess the degree to which different raters give consistent estimates of the same phenomenon, and test-retest reliability, used to assess the consistency of a measure from one time to another, were not assessed. These reliability analyses were not feasible because the same ratings were not given by different observers and the same test was not given twice in a short period of time. However, some information on this is already available; a systematic review of outcome measures for psoriasis reported moderate inter-rater reliability for PASI and PGA, high inter-rater reliability for BSA, and limited test-retest reliability for PASI, BSA, and PGA. ${ }^{4}$

Future studies should include evaluation of $\mathrm{PGA} \times \mathrm{BSA}$ (including response to change) in patients with mild-tomoderate psoriasis. Our expectation is that PGA $\times$ BSA will be more sensitive than PASI to differences in BSA in these patients. In our previous publication, we gave an example of two patients with identical PGA scores of 3; patient 1 had 


\section{A}

PASI50 and PGA $\times$ BSA50

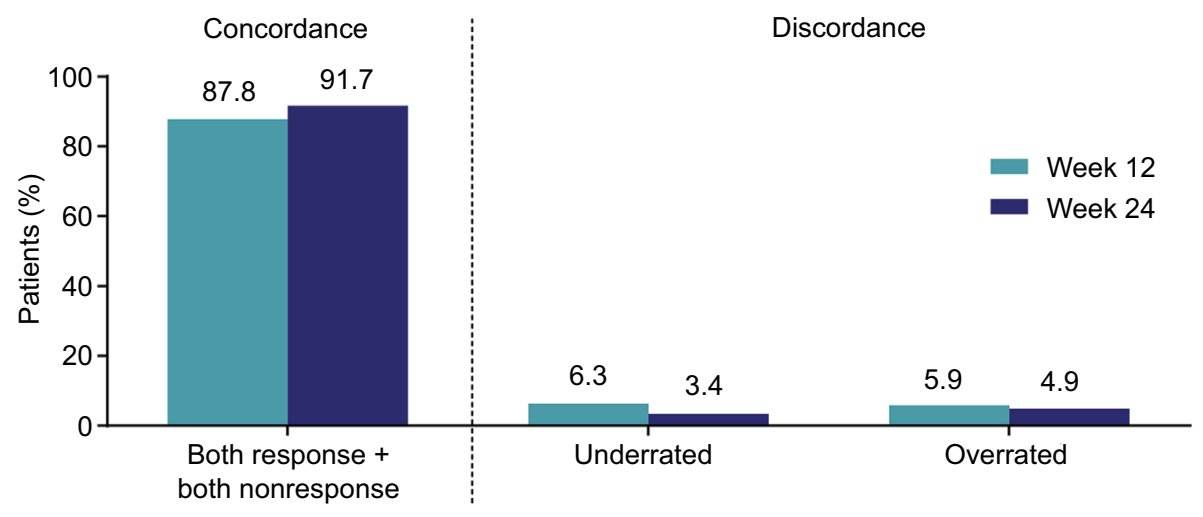

B

PASI75 and PGA $\times$ BSA75

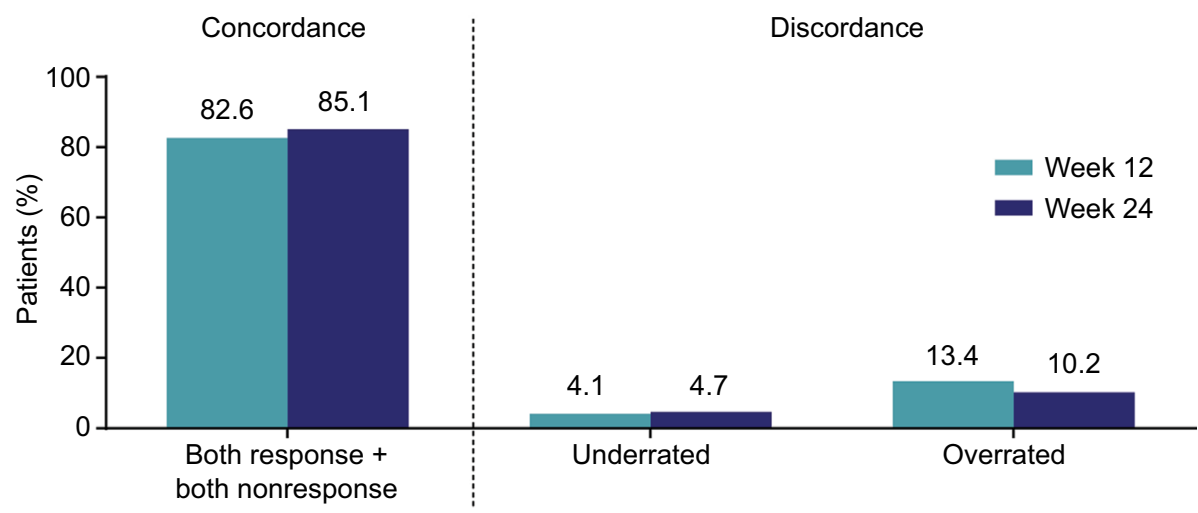

C

PASI90 and PGA $\times$ BSA90

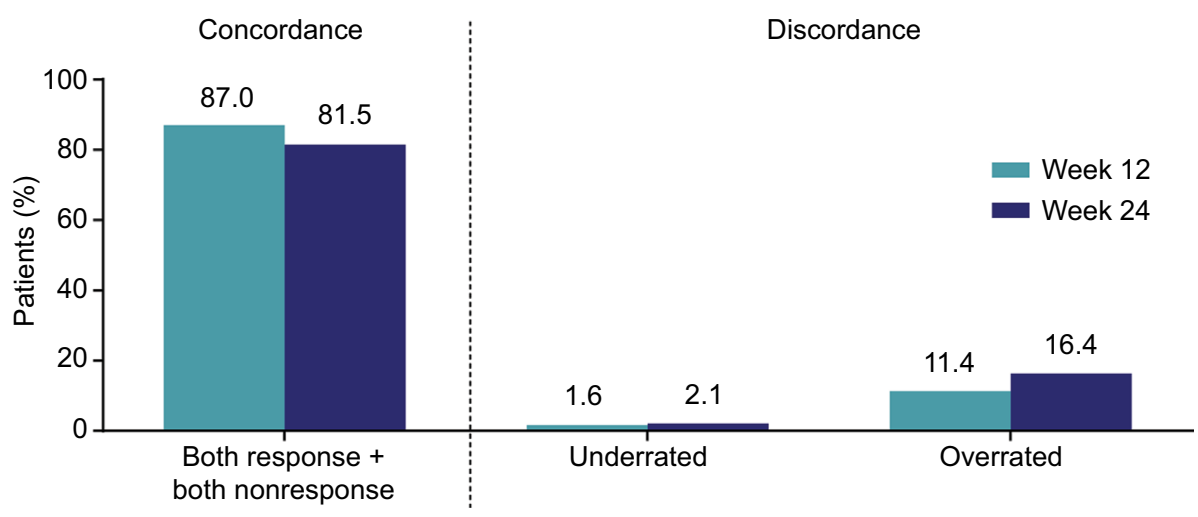

Figure 3 Concordance and discordance between PASI50 and PGA $\times$ BSA50 (A), PASI75 and PGA $\times$ BSA75 (B), and PASI90 and PGA $\times$ BSA90 (C). Concordance included the total number of patients who achieved both PASI and PGA $\times$ BSA response or both PASI and PGA $\times$ BSA nonresponse, underrated responses included patients who achieved PASI response and PGA $\times$ BSA nonresponse, and overrated responses included patients who achieved PASI nonresponse and PGA $\times$ BSA response.

Abbreviations: BSA, Body Surface Area; PASI, Psoriasis Area and Severity Index; PGA, Physician Global Assessment.

erythema 3, induration 3, and desquamation 3 and a BSA of $1 \%$, and patient 2 had identical lesion severity scores but a BSA of $9 \%$; they would have an identical PASI score of 9 as both BSA values would come under the $<10 \%$ range and thus be considered equal in the calculation. ${ }^{2}$ In contrast, PGA $\times$ BSA scores would reflect their different disease states, with a score of 3 for patient 1 and 27 for patient 2 . This sensitivity is most pronounced with mild disease, since there is a larger relative difference between $9 \%$ and $1 \%$ BSA ( $9 \times$ greater BSA) than between $29 \%$ and $21 \%$ BSA (1.4× greater BSA). PASI is limited by unequally distributed area score groupings that are not consistently sensitive 
Table 3 Correlations between other measures of psoriasis severity and PGA $\times$ BSA

\begin{tabular}{|c|c|c|c|c|c|c|c|c|}
\hline \multirow[t]{2}{*}{ Time } & \multicolumn{2}{|c|}{$\begin{array}{l}\text { BSA versus } \\
\text { PGA } \times \text { BSA }\end{array}$} & \multicolumn{2}{|c|}{$\begin{array}{l}\text { PGA versus } \\
\text { PGA } \times \text { BSA }\end{array}$} & \multicolumn{2}{|c|}{$\begin{array}{l}\text { PtGA versus } \\
\text { PGA } \times \text { BSA }\end{array}$} & \multicolumn{2}{|c|}{$\begin{array}{l}\text { DLQI versus } \\
\text { PGA } \times \text { BSA }\end{array}$} \\
\hline & $\mathbf{n}$ & $r$ & $\mathbf{n}$ & $r$ & $\mathbf{n}$ & $r$ & $\mathbf{n}$ & $r$ \\
\hline Baseline & 510 & 0.96 & 510 & 0.51 & 505 & 0.19 & 508 & 0.17 \\
\hline Week 12 & 495 & 0.95 & 495 & 0.80 & 495 & 0.40 & 493 & 0.37 \\
\hline Week 12 CFB & 495 & 0.88 & 495 & 0.59 & 490 & 0.24 & 493 & 0.22 \\
\hline Week 24 & 472 & 0.97 & 472 & 0.88 & $47 I$ & 0.52 & 470 & 0.51 \\
\hline Week 24 CFB & 472 & 0.91 & 472 & 0.49 & 466 & 0.26 & 470 & 0.21 \\
\hline
\end{tabular}

Notes: $P<0.00$ I for all Spearman correlations. Data are for observed cases. Week $12 / 24$ CFB in PGA $\times$ BSA was calculated as week $12 / 24$ PGA $\times$ BSA - baseline PGA $\times$ BSA. The scale for PtGA in the PRESTA study was converted from 0-100 to 0-5 by dividing by 20 .

Abbreviations: BSA, Body Surface Area; CFB, change from baseline; DLQI, Dermatology Life Quality Index; PGA, Physician Global Assessment; PtGA, Patient Global Assessment; $r$, Spearman correlation coefficient.

to clinically meaningful differences in area involvement (for example, 1 for up to $10 \%$ BSA, 2 for $10 \%-29 \%, 3$ for $30 \%-49 \%$, 4 for $50 \%-69 \%$, 5 for $70 \%-89 \%$, and 6 for $\geq 90 \%$ ). With PGA $\times$ BSA, this limitation is avoided with a continuous area score (for example, $0 \%-100 \%$ ), which enables improved monitoring of treatment efficacy over time in clinical practice. Under some circumstances, the PGA $\times$ BSA score may be the same despite different combinations of PGA and BSA: for example, a PGA of 5 and BSA of 4 versus PGA of 1 and BSA of 20 (PGA $\times$ BSA is 20 for both). For such patients, the PGA $\times$ BSA score can easily be deconstructed into component scores to facilitate clinical judgment.

\section{Conclusion}

In conclusion, $\mathrm{PGA} \times \mathrm{BSA}$ is a sensitive tool for assessing psoriasis severity and response to therapy. While not interchangeable, $\mathrm{PGA} \times \mathrm{BSA}$ and PASI had high agreement, and PGA $\times$ BSA has the advantage of being practical for use in both clinical practice and clinical trials.

\section{Acknowledgments}

We are grateful to the Marriott Daughters Foundation and the Ben B and Iris M Margolis Foundation for supporting Dr Walsh's work. We wish to thank all patients who participated in this study and medical staff of all participating centers. Medical writing support was provided by Rina Vekaria Passmore of Engage Scientific Solutions and was funded by Pfizer. This study was sponsored by Pfizer.

Preliminary data from this study were presented as a poster at the European Academy of Dermatology and Venereology 23rd Congress, October 8-12, 2014, Amsterdam (abstract published in the official congress abstract CD ROM) and the Australasian College of Dermatologists 48th Annual Scientific Meeting, May 16-19, 2015, Adelaide (abstract published in the Australasian Journal of Dermatology. 2015;56(Suppl 2):45; available from: https://onlinelibrary. wiley.com/doi/epdf/10.1111/ajd.12337).

\section{Author contributions}

All authors contributed toward data analysis, drafting and revising the paper and agreed to be accountable for all aspects of the work.

\section{Disclosure}

Jessica A Walsh has received honoraria for serving as a consultant for Novartis. Heather Jones is an employee of Pfizer and has a financial interest in Pfizer. Lotus Mallbris was employed by Pfizer at the time of the analysis and has a financial interest in Pfizer. Kristina Callis Duffin/her institution has received a salary for serving as an investigator for AbbVie, Amgen, Bristol-Myers Squibb, Celgene, Eli Lilly, Janssen, Novartis, and Stiefel, honoraria for serving as a consultant for AbbVie, Amgen, Bristol-Myers Squibb, Celgene, Eli Lilly, Janssen, Novartis, Pfizer, and Stiefel, and fellowship funding for serving as a consultant for AbbVie. Gerald G Krueger has received honoraria for serving as an advisory board member or consultant or speaker for AbbVie, Amgen, Boehringer Ingelheim, Bristol-Myers Squibb, Celgene, Genentech, Janssen, Eli Lilly, L'Oreal, Novartis, Pfizer, $\mathrm{UCB}$, and Valeant. Daniel O Clegg has received honoraria as a consultant for Janssen Pharmaceuticals. Annette Szumski is an employee of inVentiv Health and was contracted by Pfizer to provide statistical support for the development of this paper. The authors report no other conflicts of interest in this work.

\section{References}

1. Gottlieb AB, Armstrong AW. Psoriasis outcome measures: a report from the GRAPPA 2012 annual meeting. J Rheumatol. 2013;40(8): 1428-1433. 
2. Walsh JA, McFadden M, Woodcock J, et al. Product of the physician global assessment and body surface area: a simple static measure of psoriasis severity in a longitudinal cohort. J Am Acad Dermatol. 2013;69(6): 931-937.

3. Pascoe VL, Enamandram M, Corey KC, et al. Using the physician global assessment in a clinical setting to measure and track patient outcomes. JAMA Dermatol. 2015;151(4):375-381.

4. Puzenat E, Bronsard V, Prey S, et al. What are the best outcome measures for assessing plaque psoriasis severity? A systematic review of the literature. J Eur Acad Dermatol Venereol. 2010;24(Suppl 2):10-16.

5. Robinson A, Kardos M, Kimball AB. Physician global assessment (PGA) and Psoriasis Area and Severity Index (PASI): why do both? A systematic analysis of randomized controlled trials of biologic agents for moderate to severe plaque psoriasis. J Am Acad Dermatol. 2012;66(3):369-375.

6. Spuls PI, Lecluse LL, Poulsen ML, Bos JD, Stern RS, Nijsten T. How good are clinical severity and outcome measures for psoriasis? Quantitative evaluation in a systematic review. J Invest Dermatol. 2010;130(4):933-943.

7. Au SC, Madani A, Alhaddad M, Alkofide M, Gottlieb AB. Comparison of the efficacy of biologics versus conventional systemic therapies in the treatment of psoriasis at a comprehensive psoriasis care center. J Drugs Dermatol. 2013;12(8):861-866.

8. Buzney CD, Peterman C, Saraiya A, et al. Clearance of psoriasis: the impact of private versus public insurance. J Drugs Dermatol. 2015;14(2):119-125.

9. Chiesa Fuxench ZC, Callis Duffin K, Siegel M, Van Voorhees AS, Gelfand JM. Validity of the Simple-Measure for Assessing Psoriasis Activity (S-MAPA) for objectively evaluating disease severity in patients with plaque psoriasis. J Am Acad Dermatol. 2015;73(5):868-870.
10. Duffin KC, Papp KA, Bagel J, Levi E, Chen R, Gottlieb AB. Evaluation of the physician global assessment and body surface area composite tool for assessing psoriasis response to apremilast therapy: results from ESTEEM 1 and ESTEEM 2. J Drugs Dermatol. 2017;16(2): $147-153$.

11. Sorensen EP, Fanucci KA, Saraiya A, et al. Tumor necrosis factor inhibitor primary failure predicts decreased ustekinumab efficacy in psoriasis patients. J Drugs Dermatol. 2015;14(8):893-898.

12. Strohal R, Puig L, Chouela E, et al. The efficacy and safety of etanercept when used with as-needed adjunctive topical therapy in a randomised, double-blind study in subjects with moderate-to-severe psoriasis (the PRISTINE trial). J Dermatolog Treat. 2013;24(3):169-178.

13. Sterry W, Ortonne JP, Kirkham B, et al. Comparison of two etanercept regimens for treatment of psoriasis and psoriatic arthritis: PRESTA randomised double blind multicentre trial. BMJ. 2010;340:c147.

14. Fredriksson T, Pettersson U. Severe psoriasis - oral therapy with a new retinoid. Dermatologica. 1978;157(4):238-244.

15. Finlay AY. Current severe psoriasis and the rule of tens. Br J Dermatol. 2005;152(5):861-867.

16. Chow R, Chiu N, Bruera E, et al. Inter-rater reliability in performance status assessment among health care professionals: a systematic review. Ann Palliat Med. 2016;5(2):83-92.

17. Fantoni M, Izzi I, Del Borgo C, et al. Inter-rater reliability of a modified Karnofsky Scale of Performance Status for HIV-infected individuals. Aids Patient Care STDS. 1999;13(1):23-28.

18. Landis JR, Koch GG. The measurement of observer agreement for categorical data. Biometrics. 1977;33(1):159-174.

19. Fleiss JL. Statistical Methods for Rates and Proportions. 2nd ed. New York, NY: John Wiley; 1981. 


\section{Supplementary materials}

Table SI PRISTINE Trial (NCT00663052): names and addresses of IRBs or IECs

Country
IRB/IEC name and address

\section{Argentina}

CEPI Comité de Ética de Protocolos de

site(s) No.

Investigación,

Hospital Italiano de Buenos Aires

Gascon 450, Capital Federal, Zip code: CI I99ABB,

Argentina

Comité de Ética Independiente para Ensayos en

Farmacología Clínica

J.E Uriburu 774 Ipiso Zip code: C1027AAP,

Capital Federal, Argentina

\section{Austria}

Etikkommission der Stadt Wien

Thomas - Klestil Platz 8

Town Town I. Stock, 1030 Wien

\section{Belgium}

Commission d'Éthique Biomédicale Hospitalo-

Facultaire

Avenue Hippocrate 55. 14 Tour Harvey - niveau 0

I200 Bruxelles

Leading EC is the EC of Ghent (site 002): Ethics

Committee UZ Ghent

De Pintelaan 185

9000 Ghent

\section{Czech Republic}

Etická Komise Nemocnice Jihlava Vrchlickeho 59,

586 33, Jihlava, Czech Republic

Lokalni Eticka Komise Fakultni nemocnice Plzen

Edvards Benese 13,

30599 Plzen-Bory, Czech Republic

Multicentrieka eticka Komise Fakultni nemocnice u

sv. Anny v Brne

Pekarska 53, 656 91, Brno, Czech Republic

Germany

Ethikkommission des Fachbereichs Medizin

der Johann Wolfgang von Goethe-Universität

Frankfurt Haus I

Theodor-Stern-Kai 760590 Frankfurt am Main

Greece

National Ethics Committee 284 Mesogeion Ave.,

15562 Holargos

Hungary

Debreceni Egyetem Orvos-és Egészségfudományi

Centrum

Tudományos Bizottságának Regionális és Intézményi

Etikai Bizottsága

Nagyerdei Krt. 98. H-40 I2, Debrecen, Hungary

Egészségügyi Tudományos Tanács Klinikai

Farmakológiai Etikai Bizottsága

Arany János utca 6-8. Budapest, $\mathrm{H}-105 \mathrm{I}$ Hungary

Miskolci Egészségügyi Központ és Egyetemi

Oktatókórház

Intézeti Kutatásetikai Bizottság

H-350I, Miskolc, Csabai kapu 9-II., Hungary

014

04I

016

008

032, 033, 034,

$039,040,048$,

049

018

007

006, 007, 046,

047

006
Table SI (Continued)

\section{Country}

IRB/IEC name and address

Investigational site(s) No.

Semmelweis Egyetem

047

Intézményi Kutatásetikai Bizottsága 1091, Budapest,

Üllöi út 93 Hungary

Szegedi Tudományegyetem Szent-Györgyi Albert

046

Klinikai Központ

Regionális és Intézményi Humán Orvosbiológiai

Kutatásetikai Bizottsága

013, 045 6720, Szeged, Korányi fasor 8-10 Hungary

Italy

Comitato Etico

021

Azienda USL 4 L'Aquilla

P.O. San Salvatore

036, $037 \quad$ loc. Coppito 67100 - L’Aquila Italy

Korea

Institutional Review Board Samsung Medical Center

BIII, Annex, Samsung Medical Center,

50 llwon-dong, Kangnam-gu,

Seoul, I35-710 Korea

Seoul National University College of Medicine/Seoul

National University Hospital Institutional Review

002, 04I Board

IRB, Clinical Research Institute, Seoul National

University Hospital, 28 Yeongeon-dong,

Jongno-gu, Seoul, I I 0-744 Korea

\section{Mexico}

Comité de Ética de la Facultad de Medicina de la

042

UANL $y$

Hospital Universitario "Dr. José Eleuterio González"

UANL (Dermatology Department)

Av. Francisco I. Madero poniente $s / n$ y Av.

008, 016 Gonzalitos Col. Mitras Centro, Monterrey, Nuevo

León CP 64460

Comité de Ética del Instituto Dermatologico de

Jalisco "Dr. José Barba Rubio".

Av. Federalismo Nte. No. 3102 Atemajac del Valle

CP. 45190

Zapopan Jalisco Mexico

Unidad de Investigacion Clinica e Medicina SC

Edificio Delta

Av. La Clinica \# 2520 Despacho 520 Monterrey NL,

CP 647I0

Mexico

Spain

CEIC del Hospital de la Santa Creu I Sant Pau Av.

San Antonio M ${ }^{\mathrm{a}}$ Claret, 167

08025 Barcelona

Taiwan

Research Ethics Committee of National Taiwan

University Hospital,

B4 Floor, No.7, Chung-San South Rd, Taipei 100,

Taiwan

The Institutional Review Board of Taipei Medical

University Hospital

252, Wu Hsing Street, Taipei, Taiwan, ROC 
Table SI (Continued)

\section{Country}

IRB/IEC name and address

Investigational

site(s) No.

\section{Thailand}

Ethical Clearance Committee On Human Rights To

027

Researches Involving Human Subjects Faculty Of

Medicine,

Ramathibodi Hospital, Mehidol University

3rd Floor, Research And Welfare Building,

Ramathibodi Hospital, Rama 6 Road,

Rajthevi, Bangkaok 10400

Thailand

Reserarch Affairs Faculty Of Medicine

Division Of Research Affairs

$3^{\text {rd }}$ Floor, Anandha Mahidol Building

Faculty OF Medicine,

Chulalongkorn University

Rama 4 Road, Pathumwan,

Bangkok 10330,

Thailand

Note: This post hoc analysis utilised data from old studies. IRB/EC names could be recovered for the PRISTINE (NCT00663052), but not PRESTA trial (NCT00245960). Abbreviations: IRB, Institutional Review Boards; IEC, Independent Ethics Committees.

\section{Publish your work in this journal}

Psoriasis: Targets and Therapy is international, peer-reviewed, open access journal focusing on psoriasis, nail psoriasis, psoriatic arthritis and related conditions, identification of therapeutic targets and the optimal use of integrated treatment interventions to achieve improved outcomes

and quality of life. Visit http://www.dovepress.com/testimonials.php to read real quotes from published authors 